\title{
Prognostic Value of Negative Lymph Nodes (NLN) in Rectal Adenocarcinoma
}

\author{
Amir A. Fikry ${ }^{1}$, Niveen A. Abo-Touk ${ }^{2}$ \\ ${ }^{1}$ Departement of General Surgery, Faculty of Medicine, Mansoura University, Mansoura, Egypt \\ ${ }^{2}$ Departement of Clinical Oncology and Nuclear Medicine, Faculty of Medicine, Mansoura University, Mansoura, Egypt
}

Email address:

amrikry@yahoo.com (A. A. Fikry), nivabotouk@gmail.com (N. A. Abo-Touk)

\section{To cite this article:}

Amir A. Fikry, Niveen A. Abo-Touk. Prognostic Value of Negative Lymph Nodes (NLN) in Rectal Adenocarcinoma. Journal of Surgery. Vol. 3, No. 6, 2015, pp. 71-76. doi: 10.11648/j.js.20150306.14

\begin{abstract}
We studied the impact on prognosis by negative LN (NLN) harvest count on rectal cancer patients, using immunohistochemistry to exclude micrometastasis in nodes negative by hematoxylin and eosin (H \& E) stain. A prospective study including 114 patients in Mansoura university hospitals between 2005-2008 aged 18 years or older who were diagnosed as having localized invasive adenocarcinoma rectum with stage I, II \& III was conducted. Close follow up done in both surgery department and department of clinical oncology and nuclear medicine for 5 years. We examined patient survival in relation to the negative lymph node count. Our results revealed that the number of negative lymph nodes could affect significantly survival curves where the disease free survival and overall survival were significantly better among the group of patients with more than ten negative LNs $(\mathrm{P}=0.021 \& 0.012$ respectively). In conclusion, the negative lymph node count is associated with improved survival of rectal cancer patients.
\end{abstract}

Keywords: Rectal Cancer, Negative LN, Survival

\section{Introduction}

Rectal carcinoma appears to comprise a number of individual disease entities with different physiologic characteristics and probabilities of metastasis [22]. Of all the features of the disease examined, in nonmetastatic colorectal cancer, lymph node status is the strongest pathologic predictor of patient outcome [25, 26]. Many studies have correlated improved survival with increasing number of retrieved lymph nodes [7, 36]. Improved outcomes were referred to more accurate staging, which reflected the true node status of the patient, subsequently lead to appropriately utilized chemotherapy. However, other studies have challenged this hypothesis [4, 32]. Papers reported significantly increased overall survival and disease free survival as the number of lymph nodes retrieved increased regardless of whether the lymph nodes were positive or negative for metastatic disease [7, 32]. The total number of LNs (TLNs) retrieved encompass both positive (PLNs) and negative LNs (NLNs), so the relationship between TLNs and prognosis is confounded by the prognostic effect of the number of positive LNs [32]. The concept of NLN counts has recently attracted attention as a prognostic indicator in colon [20], gastric [13], esophageal [45], cervical [6] and breast cancer [39] but still little is known with respect to its prognostic significance. This study was designed to clarify this issue.

\section{Materials and Methods}

A prospective study including 114 Patients In mansoura university hospitals between 2005-2008 included patients aged 18 years or older who were diagnosed with localized invasive adenocarcinoma rectum with stage I, II, III. Tumour stage was based on TNM staging system and American Joint Committee on Cancer this has been recently updated as its seventh edition and is detailed elsewhere [16, 17]. We excluded in situ, metastatic, mucinous tumours, obstructing tumours and cancers on top of inflammatory bowel disease. Patients with less than total $12 \mathrm{LN}$ harvest (College of American Pathologists consensus statement 1999) [8] and those with preoperative radiotherapy also excluded as it lower the number of LN retrieved and fewer LN metastasis [24, 38, 42, 44]. Operative procedures were conducted as usual: low anterior resection or abdominoperineal operation according to the site of the tumour with total mesorectal 
excision $[18,27]$. The specimen is examined macroscopically to detect exact site of the tumour, its configuration, extent then sections from the tumour prepared as paraffin section stained with $\mathrm{H} \& \mathrm{E}$ for the type, grade and infiltration of the bowel wall. The negative lymph nodes by hematoxylin and eosin stain then stained for CEA and cytokeratin to offer estimates of occult metastatic burden. Immunostaining technique was applied by adding anti CEA antibody to detect micrometastatic deposits of malignant cells in the lymph nodes and anticytokeratin antibody to prove its epithelial nature (figure 1) as some macrophages may absorb soluble CEA and give misinterpretation but cytokeratines were consistently absent in macrophages [10]. Patients were followed up closely in both surgery department and department of clinical oncology and nuclear medicine for 5 years. Postoperative follow up included: clinical evaluation, serum CEA, abdominal ultrasound every three months, barium enema every six months, yearly colonoscopy and CT scan. We examined patient survival in relation to the negative lymph node count and the cutoff value was 10 NLN [34]. All of statistical analyses were performed using the statistical software package SPSS for Windows, version 16 (IBM Corp, Armonk, NY, USA). Statistical significance was set at twosided $\mathrm{P}<0.05$.

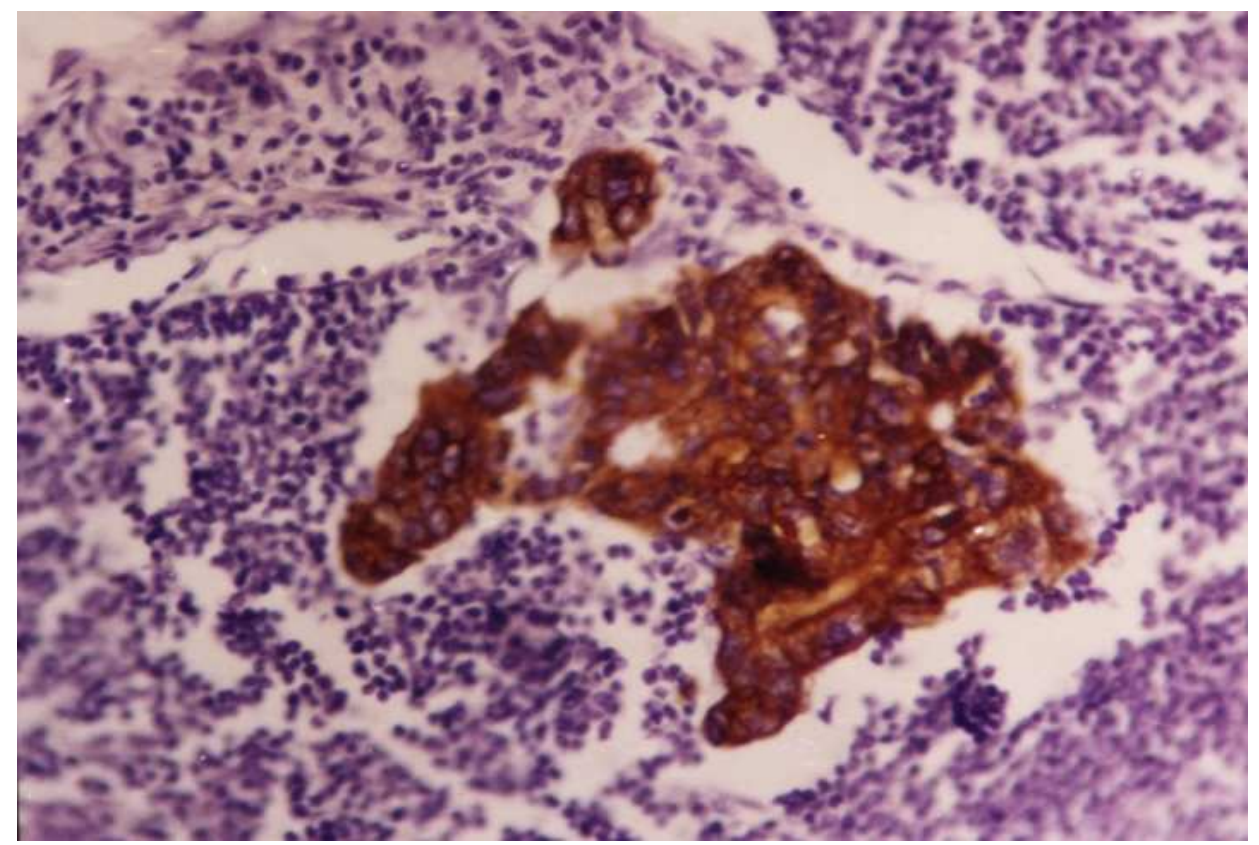

Figure 1. Grade II adenocarcinoma with focal deposits in LN positive for Cytokeratin (AntiCytokeratin antibody).

\section{Results}

A total of 114 patients fulfilled selection criteria during the 9-year study period were identified, including 61 male $(53.5 \%)$ and 53 female $(46.5 \%)$ patients. Peak age among patients was between 50 and 60 years $(48.2 \%)$ ranging from 18 to 72 years. The main presentation was bleeding per rectum $(65 \%)$. Tumours of the upper rectum represents $43 \%$, midrectum $17 \%$ while $40 \%$ of tumours in the lower rectum.

All patients with upper rectal tumours underwent anterior resection and those having lower rectal tumours together with two patients with midrectal cancer had abdominoperineal resection. There were 17 patients (15\%) with stage I, 72 patients $(63 \%)$ stage II, and 25 patients $(22 \%)$ with stage III rectal cancer. Moderately differentiated tumours were the commonest $(48 \%)$, and the least were poorly differentiated (11\%). Grossly, annular stenosing lesion was there in $50 \%$ of cases .The mean number of total lymph nodes (TLN) harvest was $14.4 \mathrm{LN}$ and that of positive (PLN) and negative lymph nodes (NLN) were $3.7 \mathrm{LN} \& 10.7 \mathrm{LN}$ respectively. The proportion of well \& moderate differentiation gradually decreased from stage I to stage III (100\% to 64\%). Patients with stage III cancer had PLNs (mean of 7.6). There were fewer NLNs in patients with stage III cancer (mean of 9) than those with stage II (mean of 11.1) or stage I (mean of 11.5) cancer (table 1).

Table 1. Demographic and pathological characteristics of our patients.

\begin{tabular}{lll}
\hline Characteristic & No (114) & \% \\
\hline Sex & & \\
Male & 61 & $53.5 \%$ \\
Female & 53 & $46.5 \%$ \\
Age & & \\
$<50$ & 36 & $31.6 \%$ \\
$50-60$ & 55 & $48.2 \%$ \\
$>60$ & 23 & $20.2 \%$ \\
Clinical presentation & & \\
Bleeding/rectum & 74 & $65 \%$ \\
Constipation & 21 & $18.4 \%$ \\
Mass & 11 & $9.6 \%$ \\
pain & 8 & $7 \%$ \\
Site of the tumour & & \\
Upper rectum & 49 & $43 \%$ \\
Mid rectum & 19 & $17 \%$ \\
Lower rectum & 46 & $40 \%$ \\
\hline
\end{tabular}




\begin{tabular}{|c|c|c|}
\hline Characteristic & No (114) & $\%$ \\
\hline \multicolumn{3}{|l|}{ Type of surgery } \\
\hline Anterior resection & 66 & $58 \%$ \\
\hline Abdominoperineal resection & 48 & $42 \%$ \\
\hline \multicolumn{3}{|l|}{ Gross examination } \\
\hline Annular stenosing lesion & 57 & $50 \%$ \\
\hline Ulcerative lesion & 48 & $42 \%$ \\
\hline Cauliflower mass & 9 & $8 \%$ \\
\hline \multicolumn{3}{|l|}{ pathological stage } \\
\hline stage I & 17 & $15 \%$ \\
\hline stage II & 72 & $63 \%$ \\
\hline stage III & 25 & $22 \%$ \\
\hline \multicolumn{3}{|l|}{ Pathological grading } \\
\hline Well differentiated & 47 & $41 \%$ \\
\hline Moderate differentiated & 55 & $48 \%$ \\
\hline Poor differentiated & 12 & $11 \%$ \\
\hline \multicolumn{3}{|c|}{ Well\&moderate differentiated tumours /stage } \\
\hline stage I & $17 / 17$ & $100 \%$ \\
\hline stage II & $69 / 72$ & $96 \%$ \\
\hline stage III & $16 / 25$ & $64 \%$ \\
\hline \multirow{4}{*}{$\begin{array}{l}\text { Mean No. of LNs dissected } \\
\text { (TLN) }\end{array}$} & \multicolumn{2}{|c|}{ 14.4 LN (range from 12-35) in all stages } \\
\hline & \multicolumn{2}{|c|}{ 13.7 LN in stage I } \\
\hline & \multicolumn{2}{|c|}{$13.8 \mathrm{LN}$ in stage II } \\
\hline & \multicolumn{2}{|c|}{ 16.6LN in stage III } \\
\hline & \multicolumn{2}{|c|}{ 3.7 LN (range from 0-8) in all stages } \\
\hline $\begin{array}{l}\text { Mean No. of positive LNs } \\
\text { (PLN) }\end{array}$ & \multicolumn{2}{|c|}{ 7.6 LN in stage III } \\
\hline \multirow{4}{*}{$\begin{array}{l}\text { Mean No. of negative LNs } \\
\text { (NLN) }\end{array}$} & \multicolumn{2}{|c|}{$10.7 \mathrm{LN}$ (range from 12-33) in all stages } \\
\hline & \multicolumn{2}{|c|}{$11.5 \mathrm{LN}$ in stage $\mathrm{I}$} \\
\hline & \multicolumn{2}{|c|}{$11.1 \mathrm{LN}$ in stage II } \\
\hline & \multicolumn{2}{|c|}{$9 \mathrm{LN}$ in stage III } \\
\hline
\end{tabular}

We examined the effect of the negative lymph node count (NLN), as the total lymph node count included positive lymph nodes, which determined tumour stage and affected patient prognosis. Negative lymph node count was a variable independent of tumour stage, so the prognostic effect of the negative lymph node count (independent of tumour stage) could be measured more accurately.

Five years of follow up by frequent clinical examination, radiological studies, endoscopy revealed that recurrence had occurred in different sites in thirty patients $(26 \%)$. Nine of them had only liver secondaries (three were candidates for successful resection). Sixteen patients had locoregional recurrences, six patients with anastmotic recurrence (reoperated upon by abdominoperineal resection), four patients showed abdominal nodal recurrence, two patient had recurrence at the wound of the perineum after abdominoperineal resection (both groups recieved chemotherapy), two patient had both liver and lung secondaries, two patient had abdominal mass and wound recurrence (both groups were not amenable for further intervention). The last five patients had liver and locoregional recurrences (resectable in one case). During follow-up, there were a total of 19 deaths, 16 were related to cancer recurrences. Kaplan Meier plots were used to assess disease free survival and overall survival according to the number of negative lymph nodes. Both five-year disease free and overall survivals were significantly higher in patients with more than 10 negative $\mathrm{LN}$ than those with less than 10 negative $\mathrm{LN}(\mathrm{P}=0.021$ and 0.012 respectively) (table 2$)$ and (figures 2, 3).

Table 2. The relation between survival and the number of negative $L N$.

\begin{tabular}{|c|c|c|c|c|c|c|}
\hline \multirow{3}{*}{ survival } & & \multicolumn{4}{|c|}{ No. of negative LN } & \multirow{3}{*}{ P value } \\
\hline & & \multicolumn{2}{|c|}{$<10$ NLN } & \multicolumn{2}{|c|}{$>10 \mathrm{NLN}$} & \\
\hline & & no. & $\%$ & No. & $\%$ & \\
\hline \multirow{3}{*}{$\begin{array}{l}\text { Disease free } \\
\text { suvival }\end{array}$} & Yes & 36 & 62.1 & 48 & 85.8 & \multirow{3}{*}{0.021} \\
\hline & No & 22 & 37.9 & 8 & 14.2 & \\
\hline & Total & 58 & 100 & 56 & 100 & \\
\hline \multirow{3}{*}{$\begin{array}{l}\text { Overall } \\
\text { suvival }\end{array}$} & Yes & 42 & 72.4 & 53 & 94.6 & \multirow{3}{*}{0.012} \\
\hline & No & 16 & 27.6 & 3 & 5.4 & \\
\hline & Total & 58 & 100 & 56 & 100 & \\
\hline
\end{tabular}

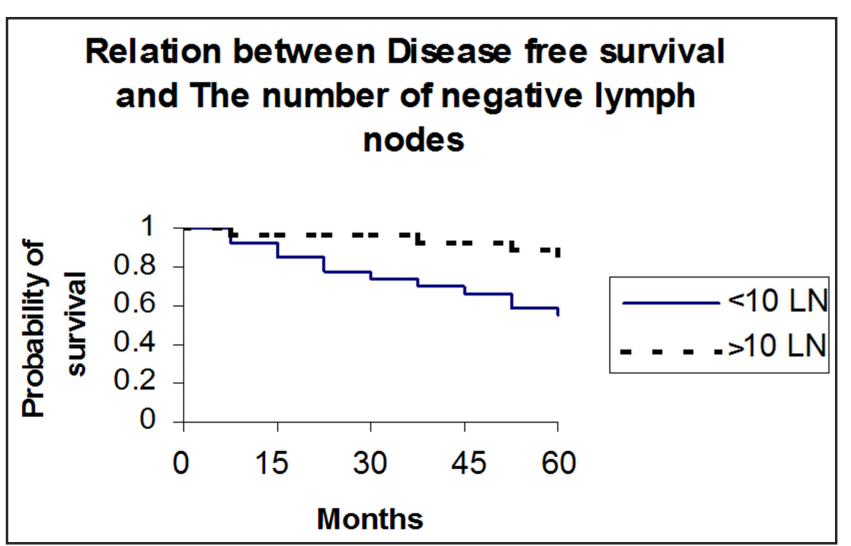

Figure 2. The relation between Disease free survival and the number of negative $L N$.

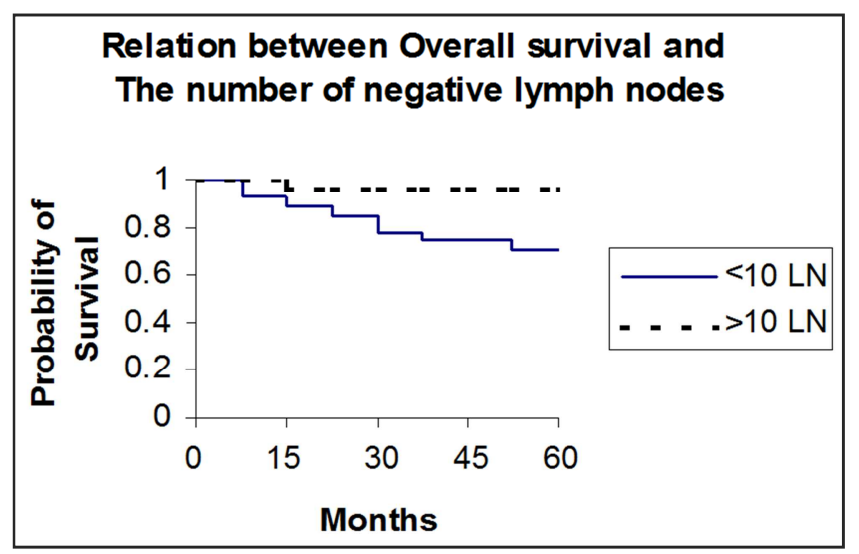

Figure 3. The relation between Overall survival and the number of negative $L N$.

\section{Discussion}

Metastasis to regional LNs is one of the most important prognostic factors of colorectal cancer [2, 23], and accurate assessment of lymph node status in patients with colorectal cancer is clearly essential in nearly all pathological staging systems for colorectal cancer. For our research, we studied the prognostic significance of the number of negative lymph nodes in stages I-III rectal cancer patients .The number of 
NLNs has been confirmed as an independent prognosis factor in colon [20], rectal cancer [34]. Qingguo $\mathrm{Li}$ and his colleagues [34] found that the number of NLNs had a weak or negligible correlation with PLN counts, which means that it was a prognostic factor independent of current metastatic LNs count-based staging. They also found a cutoff limit, after which an increase in the number of NLNs examined will not have any influence on the accuracy of staging and survival, that cutoff value is 10 NLNs and it was applied in our study. We observed a significant relation between negative lymph node count and survival, where the disease free survival and overall survival were significantly better among the group of patients with more than ten negative LNs $(\mathrm{P}=0.021 \& 0.012$ respectively).

In previous studies $[11,12,14,21,24,37,38,40,42,43,44]$, the number of recovered lymph nodes or the number of negative lymph nodes has consistently been associated with longer survival in colorectal cancer. The reasons behind the relationship between the number of NLNs and survival have not been determined, although several theories have been postulated. It may be the case that more adequate surgical excision of the tumours and lymph nodes positively affecting survival as there is less likelihood of leaving tumour cells behind and it reduces the chances of iatrogenic spread of cancer cells $[29,30]$. The second theory stated that more lymph node harvest will allow accurate staging and identify a metastatic focus with molecular detection [35], or the use of immunestaining $[9,10]$. However, this was obvious in stage I and II with less effect in stage III [34], also a greater number of detected lymph nodes could reflect better surgical resection or pathology $[3,5]$. This finding is matched with our results as lower grade tumours are less in stage III rectal cancer, also stage III patients have positive LNs and fewer negative LNs than stage I \&II. However we did not test separate stages as we have fewer patients and most of them have stage II tumours (69 out of 114 patients) so it will not be statistically of value. The third theory considered the host lymphocytic reaction to the tumour, which is associated with LN count [15]. It was found that lymphocytic reaction to tumour cells has been associated with longer survival in colorectal cancer $[28,31]$ as it may be an indicator of host immune response to tumour cells [20,31]. Greater lymphocytic reaction has been associated with high microsatellite instability proportion [1, 19] which, in turn, is associated with longer patient survival [33]. On the other hand, Shuji Ogino with his researchers [41] proved that independent of patient characteristics and other related molecular variables the effect of the negative lymph node count was apparent in all stages of disease although the benefit was significantly greater among patients with earlier pathologic stage.

\section{Conclusion}

Our study shows that the number of NLNs was an independent prognostic factor for rectal cancer patients. For survival benefit, we suggest at least 10 NLNs should be retrieved from rectal cancer patients.

\section{References}

[1] Alexander J, Watanabe T, Wu TT, Rashid A, Li S, Hamilton SR. Histopathological identification of colon cancer with microsatellite instability. Am J Pathol. 2001; 158: 527-535.

[2] Baxter NN, Virnig DJ, Rothenberger DA, Morris AM, Jessurun J, Virnig BA. Lymph node evaluation in colorectal cancer patients: a population-based study. J Natl Cancer Inst. 2005; 97: 219-225.

[3] Bilimoria KY, Bentrem DJ, Stewart AK, et al. Lymph node evaluation as a colon cancer quality measure: a national hospital report card. J Natl Cancer Inst 2008; 100: 1310-7.

[4] Bui L, Rempel E, Reeson D, et al. Lymph node counts, rates of positive lymph nodes, and patient survival for colon cancer surgery in Ontario, Canada: a population-based study. J SurgOncol 2006; 93: 439-45.

[5] Chang GJ, Rodriguez-Bigas MA, Skibber JM, et al. Lymph node evaluation and survival after curative resection of colon cancer: systematic review. J Natl Cancer Inst 2007; 99:43341 .

[6] Chen Y, Zhang L, Tian J, Ren X, Hao Q. Combining the negative lymph nodes count with the ratio of positive and removed lymph nodes can better predict the postoperative survival in cervical cancer patients. Cancer Cell Int. 2013; 13:6.

[7] Choi H, Law W, Poon J. The optimal number of lymph nodes examined in stage II colorectal cancer and impact of on outcomes. BMC Cancer [Internet] 2010 [cited 2012]; 10: [about 9 p.]. Available online: http://www. biomedcentral.com/1471-2407/10/267

[8] Compton C, Fielding L, Burgart L, et al. Prognostic factors in colorectal cancer: College of American Pathologists consensus statement 1999. Arch Pathol Lab Med 2000; 124: 979-94.

[9] Curtin K, Slattery ML, Holubkov R, et al. p53 alterations in colon tumours: a comparison of $\mathrm{SSCP} /$ sequencing and immunohistochemistry. Appl Immunohistochem Mol Morphol 2004; 12: 380-6.

[10] Cutait R, Alves AVF, Lopes LC, et al. Restaging of colorectal cancer based on the identification of lymph node micrometastases through immunoperoxidase staining of CEA and cytokeratins. Dis Colon Rectum 1991; 34: 917.

[11] Damin DC, Rosito MA, Contu PC, Tarta C, Ferreira PR, Kliemann LM, Schwartsmann G. Lymph node retrieval after preoperative chemoradiotherapy for rectal cancer. J Gastrointest Surg. 2012; 16: 1573-1580.

[12] de Campos-Lobato LF, Stocchi L, de Sousa JB, Buta M, Lavery IC, Fazio VW, Dietz DW, Kalady MF. Less than 12 nodes in the surgical specimen after total mesorectal excision following neoadjuvant chemoradiation: it means more than you think!. Ann SurgOncol. 2013; 20: 3398-3406.

[13] Deng J, Liang H, Wang D, Sun D, Ding X, Pan Y, Liu X. Enhancement the prediction of postoperative survival in gastric cancer by combining the negative lymph node count with ratio between positive and examined lymph nodes. Ann SurgOncol. 2010; 17: 1043-1051. 
[14] Fokas E, Liersch T, Fietkau R, Hohenberger W, Beissbarth T, Hess C, Becker H, Ghadimi M, Mrak K, Merkel S, Raab HR, Sauer R, Wittekind C, Rodel C. Tumour Regression Grading After Preoperative Chemoradiotherapy for Locally Advanced Rectal Carcinoma Revisited: Updated Results of the CAO/ARO/AIO-94 Trial. J ClinOncol. 2014; 32: 1554-1562.

[15] George S, Primrose J, Talbot R, Smith J, Mullee M, Bailey D, du Boulay C, Jordan H. Will Rogers revisited: prospective observational study of survival of 3592 patients with colorectal cancer according to number of nodes examined by pathologists. Br J Cancer. 2006; 95: 841-847.

[16] Gunderson LL, Jessup JM, Sargent DJ, Greene FL, Stewart A. Revised tumour and node categorization for rectal cancer based on surveillance, epidemiology, and end results and rectal pooled analysis outcomes. J ClinOncol. 2010; 28:256263.

[17] Gunderson LL, Jessup JM, Sargent DJ, Greene FL, Stew-art AK. Revised TN categorization for colon cancer basedon national survival outcomes data. J ClinOncol 2010; 28: 264271.

[18] Havenga K, Enker WE, Norstein J, et al. Improved survival and local control after total mesorectal excision or D3 lymphadenectomy in the treatment of primary rectal cancer. Eur J SurgOncol 1999; 25: 368.

[19] Jass JR, Do KA, Simms LA, Iino H, Wynter C, Pillay SP, Searle J, Radford-Smith G, Young J, Leggett B. Morphology of sporadic colorectal cancer with DNA replication errors. Gut. 1998; 42: 673-679.

[20] Johnson PM, Porter GA, Ricciardi R, Baxter NN. Increasing negative lymph node count is independently associated with improved long-term survival in stage IIIB and IIIC colon cancer. J ClinOncol. 2006; 24: 3570-3575.

[21] Kapiteijn E, Marijnen CA, Nagtegaal ID, Putter H, Steup WH, Wiggers T, Rutten HJ, Pahlman L, Glimelius B, van Krieken JH, Leer JW, van de Velde CJ. Preoperative radiotherapy combined with total mesorectal excision for resectable rectal cancer. N Engl J Med. 2001; 345: 638-646.

[22] Laura J. Denham, Justin C. Kerstetter, Paul C. Herrmann The complexity of the count: considerations regarding lymph node evaluation in colorectal carcinoma. J Gastrointest Oncol 2012; 3(4): 342-352.

[23] Le Voyer TE, Sigurdson ER, Hanlon AL, Mayer RJ, Macdonald JS, Catalano PJ, Haller DG. Colon cancer survival is associated with increasing number of lymph nodes analyzed: a secondary survey of intergroup trial INT- 0089. J ClinOncol. 2003; 21: 2912-2919.

[24] Li QG, Li DW, Zhuo CH, Cai GX, Cai SJ. Metastatic lymph node ratio can further stratify prognosis in rectal cancer patients treated with preoperative radiotherapy: a populationbased analysis. Tumour Biol. 2014.

[25] Liefers GJ, Cleton-Jansen AM, van de Velde CJ, et al. Micrometastases and survival in stage II colorectal cancer. N Engl J Med 1998; 339: 223-8.

[26] Lips D, Koebrugge B, Liefers G, et al. The influence of micrometastases on prognosis and survival in stage I-II colon cancer patients: the Enroute+ study. BMC Surgery [Internet] 2011 [cited 2012]; 11: [about 9 p.]. Available online.

[27] Maurer CA, Renzulli P, Meyer JD, Buchler MW. Rectal carcinoma. Optimizing therapy by partial or total mesorectum removal. ZentralblChir 1999; 124 (5): 428-35.

[28] Morris M, Platell C, Iacopetta B. Tumour-infiltrating lymphocytes and perforation in colon cancer predict positive response to 5-fluorouracil chemotherapy. Clin Cancer Res. 2008; 14: 1413-1417.

[29] Ogino S, Brahmandam M, kawasaki T, et al. Combined analysis of COX-2 and p53 expressions reveals synergistic inverse correlations with microsatellite instability and $\mathrm{CpG}$ island methylator phenotype in colorectal cancer. Neoplasia 2006; 8: 458-64.

[30] Ogino S, Kawasaki T, Nosho $\mathrm{K}$, et al. LINE-1 hypomethylation is inversely associated with microsatellite instability and CpGmethylator phenotype in colorectal cancer. Int J Cancer 2008; 122: 2767-73.

[31] Pages F, Galon J, Fridman WH. The essential role of the in situ immune reaction in human colorectal cancer. J Leukoc Biol. 2008; 84: 981-987.

[32] Parsons HM, Tuttle TM, Kuntz KM, et al. Association between lymph node evaluation for colon cancer and node positivity over the past 20 years. JAMA 2011; 306: 1089-97.

[33] Popat S, Hubner R, Houlston RS. Systematic review of microsatellite instability and colorectal cancer prognosis. $\mathrm{J}$ ClinOncol. 2005; 23: 609-618.

[34] Qingguo Li, Changhua Zhuo, GuoxiangCai, Dawei Li, Lei Liang, Sanjun Cai .Increased number of negative lymph nodes is associated with improved cancer specific survival in pathological IIIB and IIIC rectal cancer treated with preoperative radiotherapy Oncotarget, 2014; 5 (23): 1245912471.

[35] Rahbari NN, Bork U, Motschall E, Thorlund K, Buchler MW, Koch M, Weitz J. Molecular detection of tumour cells in regional lymph nodes is associated with disease recurrence and poor survival in node-negative colorectal cancer: a systematic review and meta-analysis. J ClinOncol. 2012; 30: 60-70.

[36] Ratto C, Sofo L, Ippoliti M, et al. Accurate lymph-node detection in colorectal specimens resected for cancer is of prognostic significance. Dis Colon Rectum 1999; 42: 143- 54; discussion 154-8.

[37] Rodel C, Martus P, Papadoupolos T, Fuzesi L, Klimpfinger M, Fietkau R, Liersch T, Hohenberger W, Raab R, Sauer R, Wittekind C. Prognostic significance of tumour regression after preoperative chemoradiotherapy for rectal cancer. J ClinOncol. 2005; 23: 8688-8696.

[38] Rullier A, Laurent C, Capdepont M, Vendrely V, Belleannee G, Bioulac-Sage P, Rullier E. Lymph nodes after preoperative chemoradiotherapy for rectal carcinoma: number, status, and impact on survival. Am J SurgPathol. 2008; 32: 45-50.

[39] San-Gang Wu, Jia-Yuan Sun, Juan Zhou, Feng-Yan Li, Qin Lin, Huan-Xin Lin, Xun-Xing Guan and Zhen-Yu He .Number of negative lymph nodes is associated with disease-free survival in patients with breast cancer BMC Cancer (2015) 15:43.

[40] Sauer R, Becker H, Hohenberger W, Rodel C, Wittekind C, Fietkau R, Martus P, Tschmelitsch J, Hager E, Hess CF, Karstens JH, Liersch T, Schmidberger H, Raab R. Preoperative versus postoperative chemoradiotherapy for rectal cancer. N Engl J Med. 2004; 351: 1731-1740. 
[41] Shuji Ogino, Katsuhiko Nosho, NatsumiIrahara, Kaori Shima, Yoshifumi Baba, Gregory J etal. Negative Lymph Node Count Is Associated With Survival of Colorectal Cancer Patients, Independent of Tumoural Molecular Alterations and Lymphocytic Reaction. Am J Gastroenterol. 2010; 105(2): 420-433.

[42] Taflampas P, Christodoulakis M, Gourtsoyianni S, Leventi K, Melissas J, Tsiftsis DD. The effect of preoperative chemoradiotherapy on lymph node harvest after total mesorectal excision for rectal cancer. Dis Colon Rectum. 2009; 52: 1470-1474.

[43] Vecchio FM, Valentini V, Minsky BD, Padula GD, Venkatraman ES, Balducci M, Micciche F, Ricci R, Morganti
AG, Gambacorta MA, Maurizi F, Coco C. The relationship of pathologic tumour regression grade (TRG) and outcomes after preoperative therapy in rectal cancer. Int J Radiat Oncol Biol Phys. 2005; 62: 752-760.

[44] Wichmann MW, Muller C, Meyer G, Strauss T, Hornung HM, Lau-Werner U, Angele MK, Schildberg FW. Effect of preoperative radiochemotherapy on lymph node retrieval after resection of rectal cancer. Arch Surg. 2002; 137: 206-210.

[45] Zhu Z, Chen H, Yu W, Fu X, Xiang J, Li H, Zhang Y, Sun M, Wei Q, Zhao W, Zhao K. Number of Negative Lymph Nodes is Associated with Survival in Thoracic Esophageal Squamous Cell Carcinoma Patients Undergoing Three-Field Lymphadenectomy. Ann Surg Oncol. 2014. 